\title{
Tswana Speaking South Africans' Understanding of Pain Scales
}

\author{
ABSTRACT: \\ Aim: The aim of this study was to establish the validity and reliability of the Tswana \\ translations of three pain scales. \\ Design: This was a cross-sectional study to validate and test the reliability of three \\ pain scales. \\ Participants: One hundred subjects participated in the study. They were selected \\ from the back schools of five hospitals in the North-West Province of South Africa and \\ from workers in these hospitals who were employed as kitchen workers, laundry \\ workers and cleaners.
}

Method: Translation of the pain scales and the stages of cross-cultural adaptation were followed as recommended by Beaton et al (2000). Pain tolerance of the subjects was measured using a P.T.M. (pressure threshold meter). The pain scales used were the V.A.S. (visual analogue scale) one (nought and ten only), the V.A.S. (visual analogue scale) two (nought through to ten), the W.B.F. (Wong-Baker Faces pain measure) and the V.R.S. (verbal rating scale). The V.R.S. used came in two forms. The first form was written on cue cards which the subjects arranged in order and the second form was the questionnaire version of the V.R.S.

The subjects were interviewed and asked five questions relating to their back pain. Upon completion of the interview the pressure threshold of the painful area (back) was tested.

Subjects then filled in the three pain scales, namely the (V.A.S. one, V.A.S. two, the V.R.S. and lastly the W.B.F. pain scale). Approximately a third of the sample (37) was retested the following day following the same procedure as described above.

Results: There was no correlation between the pressure threshold meter readings and the pain scale measurements. Conclusion: From the statistical analysis of the results, it became apparent that the subjects tested did not have an understanding of any of the three pain scales.

Future research needs to be done in developing entirely different scales for peoples of low literacy and different language and cultural groups in South Africa.

KEYWORDS: PAIN SCALES, VISUAL ANALOGUE SCALE ONE AND TWO, VERBAL RATING SCALE, WONG-BAKER FACES PAIN SCALE, PRESSURE THRESHOLD METER, LOW LITERACY, DIFFERING CULTURE AND LANGUAGE).

\section{INTRODUCTION}

Pain is a subjective sensation and is difficult to measure, however quantifying pain provides a measure of assessing the effectiveness of treatment and also

\section{Correspondence to:}

Professor A. Stewart

Department of Physiotherapy

School of Therapeutic Sciences

Faculty of Health Sciences,

University of the Witwatersrand

7 York Avenue

Parktown 2193

Johannesburg, South Africa

Email: aimee.stewart@wits.ac.za helps when assessing the behaviour of patients' pain (Gridley and van den Dalder 2001). Pain measures provide a baseline from which to work. The quality and level of pain can be measured and recorded for future reference and for assessing the effectiveness of pain management strategies.

The validity and reliability of various measures of pain have been extensively researched in Europe, America and Asia (Bullinger et al 1998). In Africa on the other hand, very few studies have been done and most of the research into measurement of pain has been carried out using Anglo-American pain measures (Jelsma et al 2002; Olaogun et al 2003).
Their validity and reliability have not been established in an African context.

The aim of this study was to establish the validity and reliability of the Tswana translations of three pain scales (Visual Analogue Scale, Verbal Rating Scale and the Wong-Baker Faces Pain Measure) in subjects with low literacy levels and to determine the most appropriate of the three scales to use in this population.

\section{METHOD}

\section{Ethical considerations}

Permission was obtained from the management of five hospitals in the 
North-West Province of South Africa. Subjects who met the inclusion criteria were asked to sign informed consent prior to participation in the study and ethical clearance was granted by the committee for research on human subjects, of the University of the Witwatersrand Johannesburg.

\section{Subjects}

The subjects $(\mathrm{n}=100)$ were tested at five hospitals in the province.A pilot study (ten subjects) was carried out in order to test the methodology and time taken for completion of all the scales.

Approximately a third of the sample (37) was retested the following day. Inclusion criteria.

- females and males.

- cleaners, kitchen or laundry workers in all hospitals, as well as patients

- who attended the out patient departments of the various hospitals.

- education level -grade twelve and lower.

- mechanical back pain.

- Tswana speaking.

Exclusion criteria

- younger than 18 years.

- previous surgical intervention for back pain.

- serious illness (cancer, H.I.V.).

- patients suffering from any neurological or psychiatric conditions.

\section{Sample size}

Eighty to one hundred subjects gave sufficient power to test the validity and the reliability of the pain scales (there are ten items per scale) (Jensen and Turner1994).

\section{Measurement devices}

Pain tolerance of the subjects was measured using a pressure threshold meter (P.T.M.). The middle deltoid muscle was used as the normal reference for muscle (Fischer 1987) and the shin was used to provide a normal reference for bone (Fischer and Chang 1986). The pain scales tested were the V.A.S. one (nought and ten only), the V.A.S. two (nought through to ten), the WongBaker Faces pain measure and the V.R.S. The V.R.S used came in two forms. The first was written on cue cards which the subjects arranged in order and the second was the questionnaire version of the V.R.S.
Table 1: Demographic data of subjects $(n=100)$.

\begin{tabular}{|l|l|l|}
\hline Parameter & Categories & Value \\
\hline Age & n/a & $\begin{array}{l}43.9 \\
( \pm 11.18)\end{array}$ \\
\hline Sex & Male & $14 \%$ \\
& Female & $86 \%$ \\
\hline Education level & $<$ grade8 & $47 \%$ \\
& $>$ grade9 & $53 \%$ \\
\hline Group & Cleaner & $39 \%$ \\
& Kitchen & $15 \%$ \\
& Laundry & $9 \%$ \\
& O.P.D & $37 \%$ \\
\hline Area of Back & Cervical & $0 \%$ \\
& Thoracic & $31 \%$ \\
& Lumbar & $69 \%$ \\
\hline
\end{tabular}

Most of the subjects suffered from lumbar pain followed by thoracic pain. The majority of the subjects were cleaners, had a high school education and were female.

Table 2: Demographic data of subjects. Retest group $(n=37)$.

\begin{tabular}{|l|l|l|}
\hline Parameter & Categories & Value \\
\hline Age & n/a & $\begin{array}{l}40.4 \\
( \pm 8.64)\end{array}$ \\
\hline Sex & Male & $8 \%$ \\
& Female & $92 \%$ \\
\hline Parameter & $<$ grade8 & $30 \%$ \\
& $>$ grade9 & $70 \%$ \\
\hline Group & Cleaner & $54 \%$ \\
& Kitchen & $38 \%$ \\
& Laundry & $8 \%$ \\
& O.P.D & $0 \%$ \\
\hline Area of Back & Cervical & $0 \%$ \\
& Thoracic & $32 \%$ \\
& Lumbar & $68 \%$ \\
\hline
\end{tabular}

Most of the subjects suffered from lumbar pain followed by thoracic pain. The majority of the subjects were cleaners, had a high school education and were female.

Table 3: P.T.M. readings of the back correlated with the three scales $(n=100)$.

\begin{tabular}{|l|l|l|l|l|}
\hline & \multicolumn{2}{|l|}{$\begin{array}{l}\text { Maximum pressure } \\
\text { threshold. }\end{array}$} & \multicolumn{2}{l|}{$\begin{array}{l}\text { Sub-maximum pressure } \\
\text { threshold. }\end{array}$} \\
\hline Scale & $\begin{array}{l}\text { Pearson's } \\
\text { correlation } \\
\text { coefficient }\end{array}$ & $\mathbf{p}$-value & $\begin{array}{l}\text { Pearson's } \\
\text { correlation } \\
\text { coefficient }\end{array}$ & p-value \\
\hline V.A.S. 1 & -0.12 & 0.18 & -0.23 & 0.02 \\
\hline V.A.S. 2 & -0.09 & 0.36 & -0.18 & 0.07 \\
\hline V.R.S. & -0.16 & 0.10 & -0.09 & 0.40 \\
\hline W.B.F & -0.24 & 0.02 & -0.17 & 0.08 \\
\hline
\end{tabular}

All the correlation coefficients are poor indicating that the subjects have a poor understanding of all of the scales. 
Table 4: Maximum and sub-maximum pressure threshold readings correlated with the V.A.S. $1(n=37)$.

\begin{tabular}{|l|l|l|l|l|l|l|}
\hline & \multicolumn{3}{|l|}{ Maximum pressure threshold. } & \multicolumn{2}{l|}{ Sub-maximum pressure threshold. } \\
\hline Area & $\begin{array}{l}\text { Pearson's } \\
\text { correlation } \\
\text { coefficient (r) }\end{array}$ & $\mathbf{p}$-value & $\begin{array}{l}\text { Intra-class } \\
\text { correlation } \\
\text { coefficient (rho) }\end{array}$ & $\begin{array}{l}\text { Pearson's } \\
\text { correlation } \\
\text { coefficient (r) }\end{array}$ & $\mathbf{p}$-value & $\begin{array}{l}\text { Intra-class } \\
\text { correlation } \\
\text { coefficient (rho) }\end{array}$ \\
\hline Right deltoid & -0.05 & 0.76 & 0.00 & 0.16 & 0.34 & 0.12 \\
\hline Left deltoid & 0.04 & 0.82 & 0.00 & -0.12 & 0.01 & 0.40 \\
\hline Right shin & 0.12 & 0.49 & 0.00 & 0.41 & 0.01 & 0.41 \\
\hline Left shin & 0.06 & 0.73 & 0.00 & -0.08 & 0.66 & 0.00 \\
\hline Back & -0.02 & 0.00 & 0.67 & 0.53 & 0.00 & 0.52 \\
\hline
\end{tabular}

Again there is both a poor correlation and poor agreement between pressure threshold and the patient's rating of their pain in all normal areas and the painful back area.

Table 5: Correlation between maximum and sub-maximum P.T.M. readings of the back with the three scales $(n=37)$.

\begin{tabular}{|l|l|l|l|l|}
\hline & \multicolumn{2}{|l|}{$\begin{array}{l}\text { Maximum pressure } \\
\text { threshold. }\end{array}$} & \multicolumn{2}{l|}{$\begin{array}{l}\text { Sub-maximum pressure } \\
\text { threshold. }\end{array}$} \\
\hline Scale & $\begin{array}{l}\text { Pearson's } \\
\text { correlation } \\
\text { coefficient (r) }\end{array}$ & $\mathbf{p}$-value & $\begin{array}{l}\text { Pearson's } \\
\text { correlation } \\
\text { coefficient }(\mathbf{r})\end{array}$ & p-value \\
\hline V.A.S. 1 & 0.69 & 0.00 & 0.53 & 0.00 \\
\hline V.A.S. 2 & 0.62 & 0.00 & 0.64 & 0.00 \\
\hline V.R.S. & 0.53 & 0.00 & 0.48 & 0.00 \\
\hline W.B.F & 0.66 & 0.00 & 0.70 & 0.00 \\
\hline
\end{tabular}

This table shows moderate correlation between all three scales and the P.T.M (maximum and sub-maximum readings) in the retest group ( $n=37$ ). All p-values are significant.

\section{Procedure}

\section{Translation of scales}

The stages required for cross-cultural adaptation and translation of the pain scales were followed as recommended by Beaton et al (2000).

Detail of Pain scale completion

All explanations for the study were given to subjects in Tswana by a Tswana speaking research assistant.

Step 1

Subjects were taught how to use the V.A.S. (marked only with a 0 and a 10) correctly (current pain) and once this was achieved, step 2 was undertaken

Step 2

The pain threshold was measured using the Pain Threshold Meter over a pain -free area ie. the right and left deltoid and right and left shin. Maximal pain which subjects could tolerate was elicited (pressure tolerance).
The pressure reading was recorded in $\mathrm{kg} / \mathrm{cm} 2$. Subjects then rated their pain on V.A.S. one

Step 3

Subjects were then asked to order the V.R.S. This was done using cue cards. Each cue card had one sentence written on it and it was numbered on the reverse side, where subjects were not able to see the number. This made it easier for the first author to interpret the order in which the subjects put the cards. Subjects were asked to put the cue cards in order ie. from no pain to worst pain (excruciating pain).

Step 4

The pain threshold was once more measured over the normal areas. This time only sub-maximal pain was elicited (pressure threshold)
Step 5

The V.A.S. one (marked only with a 0 and a 10) was then filled in again.

Step 6

The V.R.S.was again put into order using the cue cards (as with step 3).

Step 7

Upon completion of the above steps the subjects were requested to fill in all the pain scales (V.A.S.1, V.A.S. 2, V.R.S and the W.B.F pain scale).

The measurement of the subjects' low back pain was done in the following way:

The subjects were interviewed and asked five questions relating to their back pain enabling the first author to compare the way in which the subjects described their pain relative to their ratings of pain. Subjects then completed the three pain scales.

Upon completion of the interview the pressure threshold of the painful area (back) was tested at a rate of one kilogram per centimetre squared per second.

The cervical spine was marked area one, the thoracic spine area two and the lumbar spine marked area three to enable easy interpretation of the results.The pressure tolerance (maximum pain) and the pressure threshold (sub-maximal pain) were then measured and subjects then completed the three pain scales as before. 


\section{DATA ANALYSIS}

- demographic data are presented as means and standard deviations

- Pearson's product moment correlation coefficient was used to determine the correlation between the V.A.S., V.R.S. and Wong-Baker Faces Pain Measures scales and the P.T.M.

- test-retest reliability was measured using Pearson's coefficient and Spearman's rank order coefficient

- statistical significance was considered when the $\mathrm{p}$ value was $<=0.05$.

\section{DISCUSSION}

After statistical analysis of all the data it became apparent that not one of the scales used for these subjects was more suitable than the next, although the Wong Baker scale seemed to be better understood. It appears that subjects were unsure of what was expected of them and did not understand the entire process despite the whole testing procedure being conducted in Tswana. When looking at the results of the re-test, moderate correlation was seen between all three scales and the P.T.M readings indicating the reliability of the findings.

The subjects tested all come from a previously disadvantaged group in South Africa and because of this had inferior education in the old Bantu Education system. Subjects may have lacked functional health literacy which is defined as peoples'ability to function in a health care setting using their skills in literacy and numeracy. Low functional health literacy may limit a patient's ability to comprehend, retain, recall and act on written health care measures (scales or questionnaires) with both literary and numerical content (Teutsch, C 2003).

Some subjects were confused and did not understand how to use the V.A.S. They thought that if the pain was on the right side of their body they needed to record this on the right side of the scale and that if the pain was on the left side of the body that this should be recorded on the left side of the scale. If their pain was situated centrally they recorded it in the middle of the ten centimetre line. This could be attributed to fact that their abstract thinking ability was not well developed, again this may well be due to their poor education.

Figure 1: Scatter plot of the maximum pressure pain vs the patient perception on the V.A.S. 1.

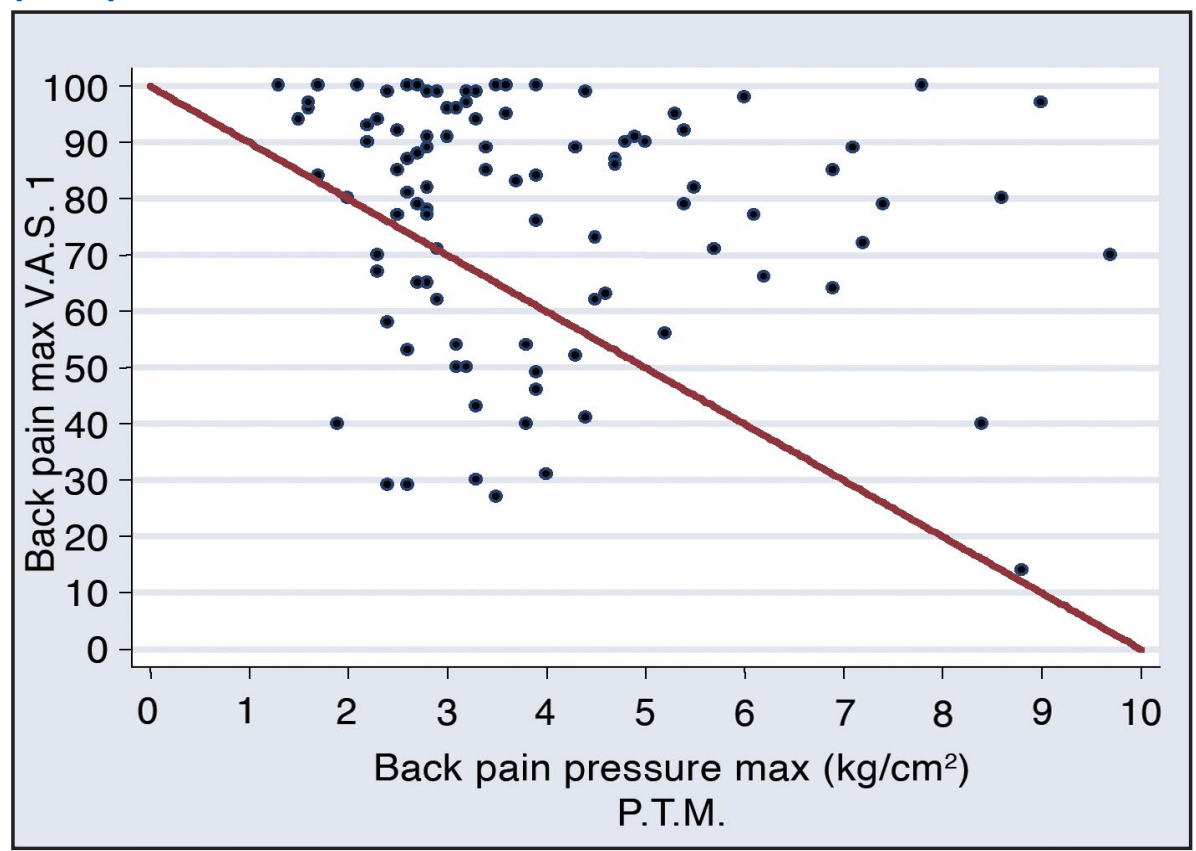

Figure 1 shows no inverse relationship exists between the maximum pressure threshold readings and the V.A.S.1.

Figure 2: Scatter plot of the maximum pressure pain vs the patient perception on the V.A.S.2.

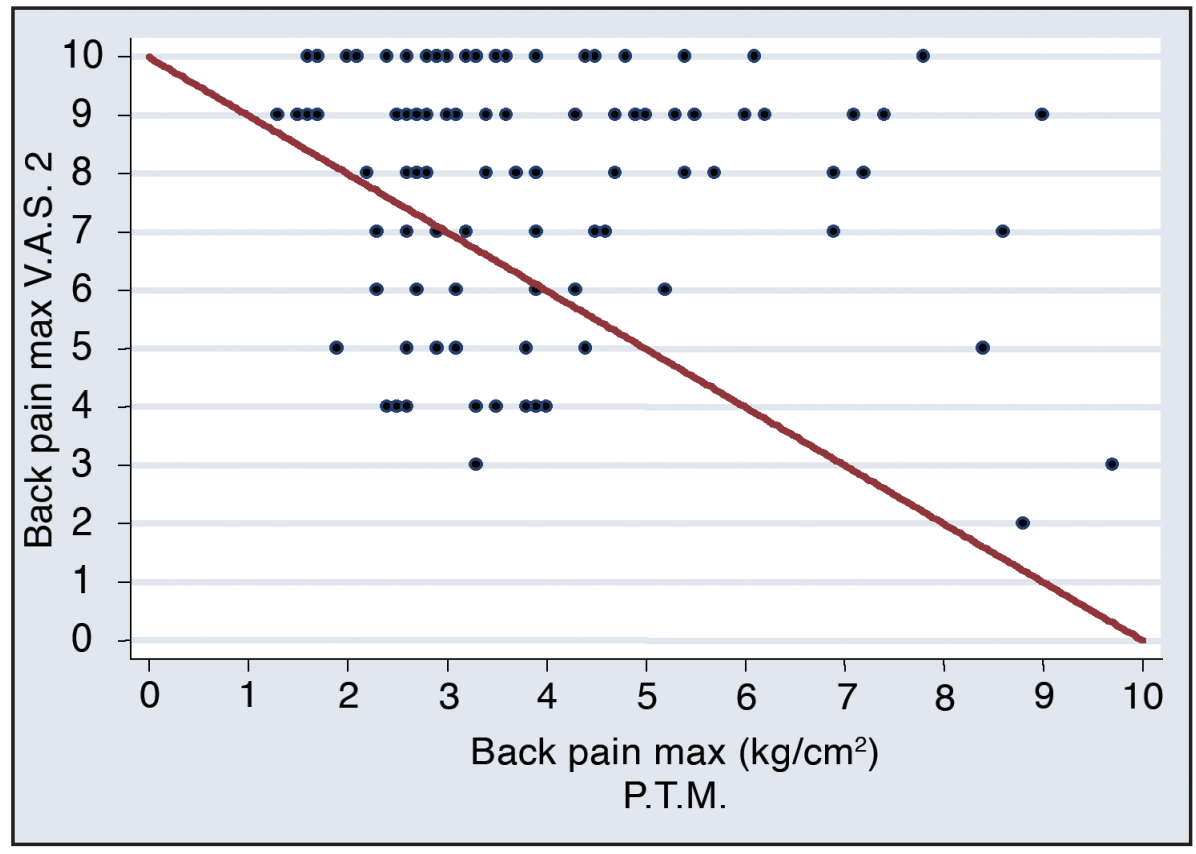

Figure 2 shows no inverse relationship exists between the maximum pressure threshold readings and the V.A.S.2.

The scale which seemed to cause the most confusion was the Verbal Rating Scale. The majority of subjects asked repeatedly during the ordering of the cue cards as to whether they were doing the right thing.
Some subjects put the cards in the wrong order i.e. arranged them from ten to nought instead of from nought to ten even after the process was explained to them more than once in their home language. Many of the subjects became 
frustrated by the entire procedure and others were embarrassed by the fact that they were not managing very well. The V.R.S. appears to be the worst understood of all the pain scales.

Future studies need to be done to develop entirely different scales for the South African population with low literacy levels. More and better understood scales should be developed for our population in order to include persons of different languages and different educational levels. This will assist in a better understanding of the health care process and as a result may then ensure better measurement of the effectiveness of health care.

\section{ACKNOWLEDGEMENTS}

The authors wish to acknowledge the assistance given by Mrs L. Jacobs and Mrs A. Nkusi; the funding by the O.M.T. group of the South African Society of Physiotherapy and the translators involved in the cross-cultural adaptation of the scales.
Figure 3: Scatter plot of the maximum pressure pain vs the patient perception on the V.R.S.

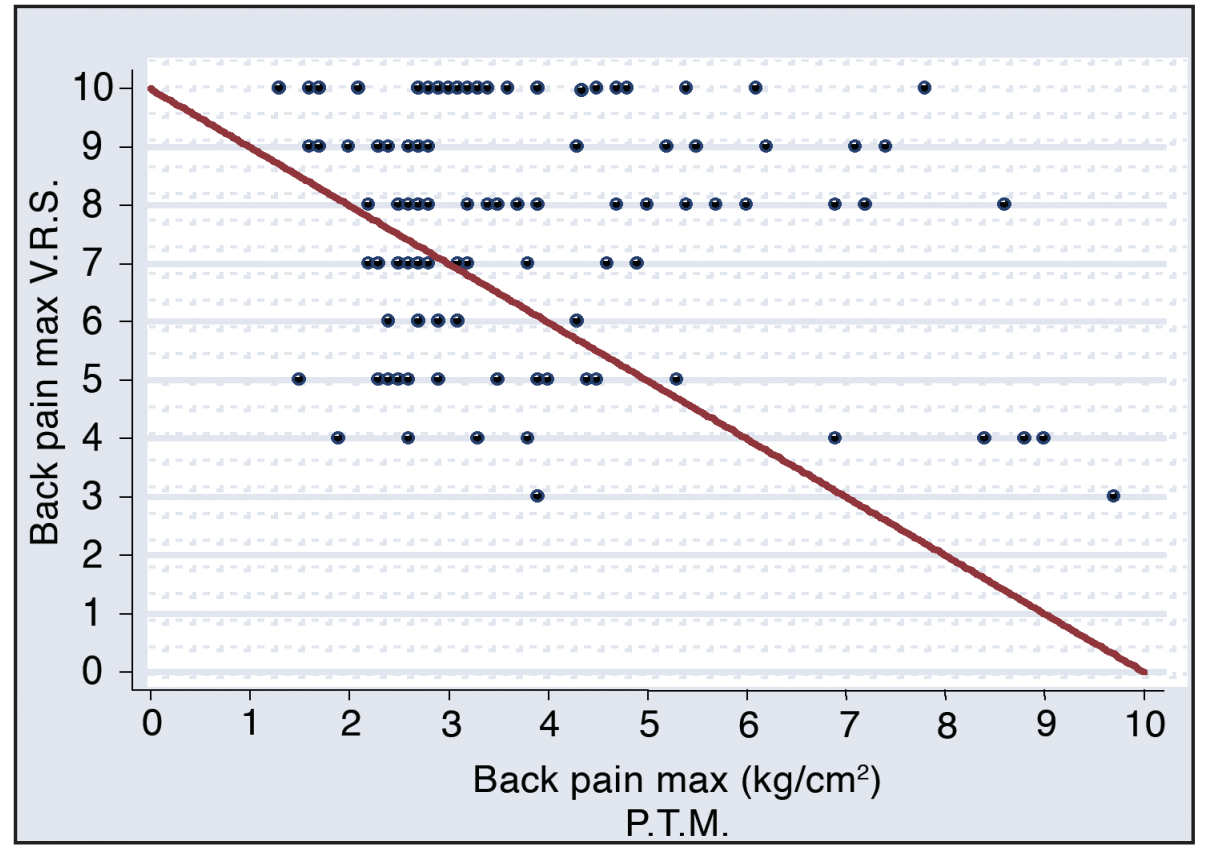

Figure 3 shows no inverse relationship exists between the maximum pressure threshold readings and the V.R.S.

Figure 4: Scatter plot of the maximum pressure pain vs the patient perception on the Wong-Baker Faces pain measure.

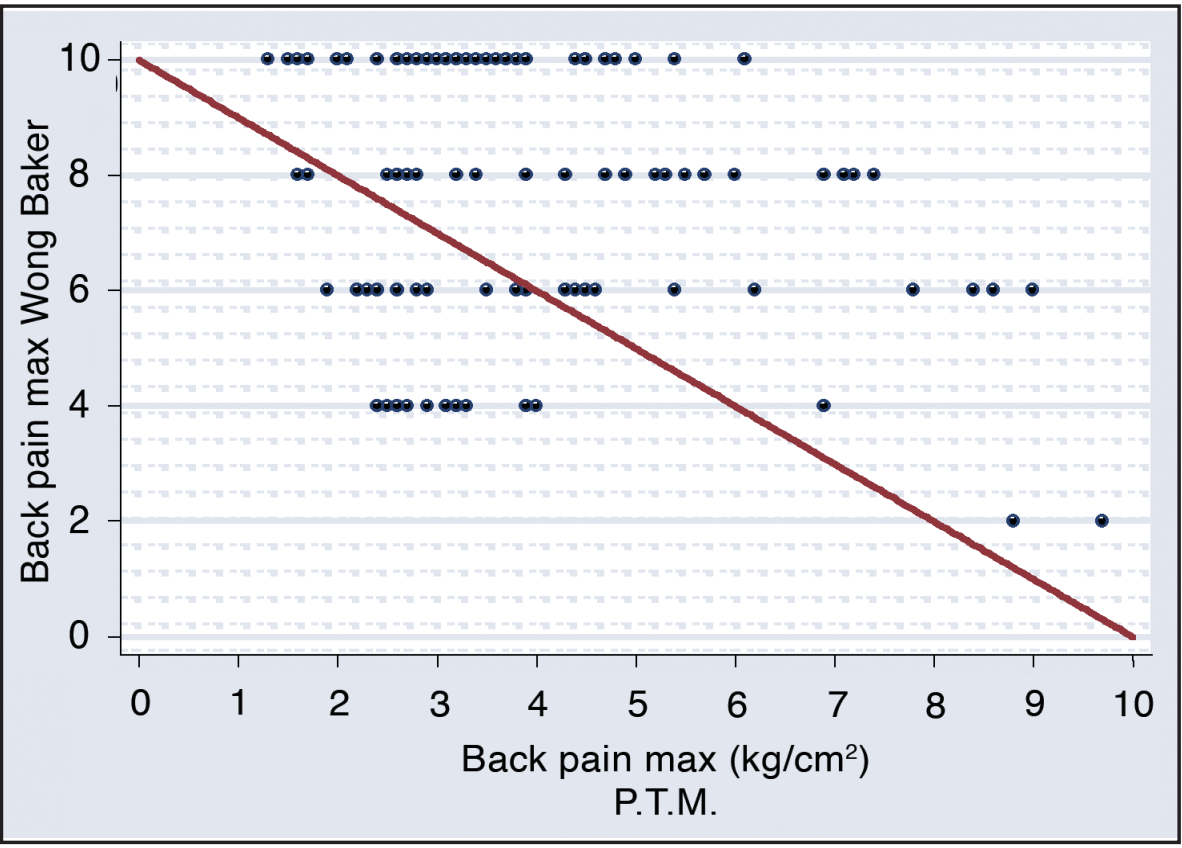

Figure 4 shows no inverse relationship exists between the maximum pressure threshold readings and the Wong-Baker Faces pain measure. 
Figure 5: Scatter plot of the sub-maximum pressure pain vs the patient perception on the V.A.S.1.

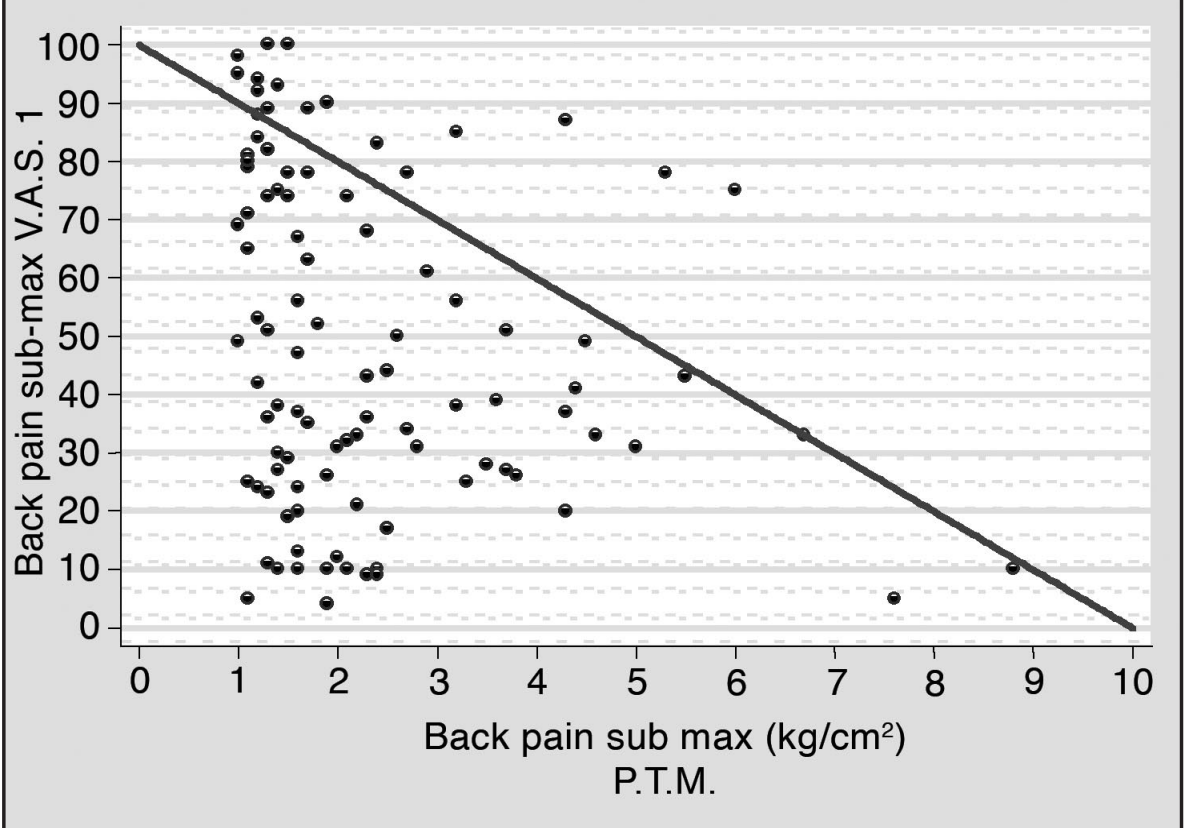

Figure 5 shows no inverse relationship exists between the sub-maximum pressure threshold readings and the V.A.S.1.

Figure 6: Scatter plot of the sub-maximum pressure pain vs the patient perception on the V.A.S.2.

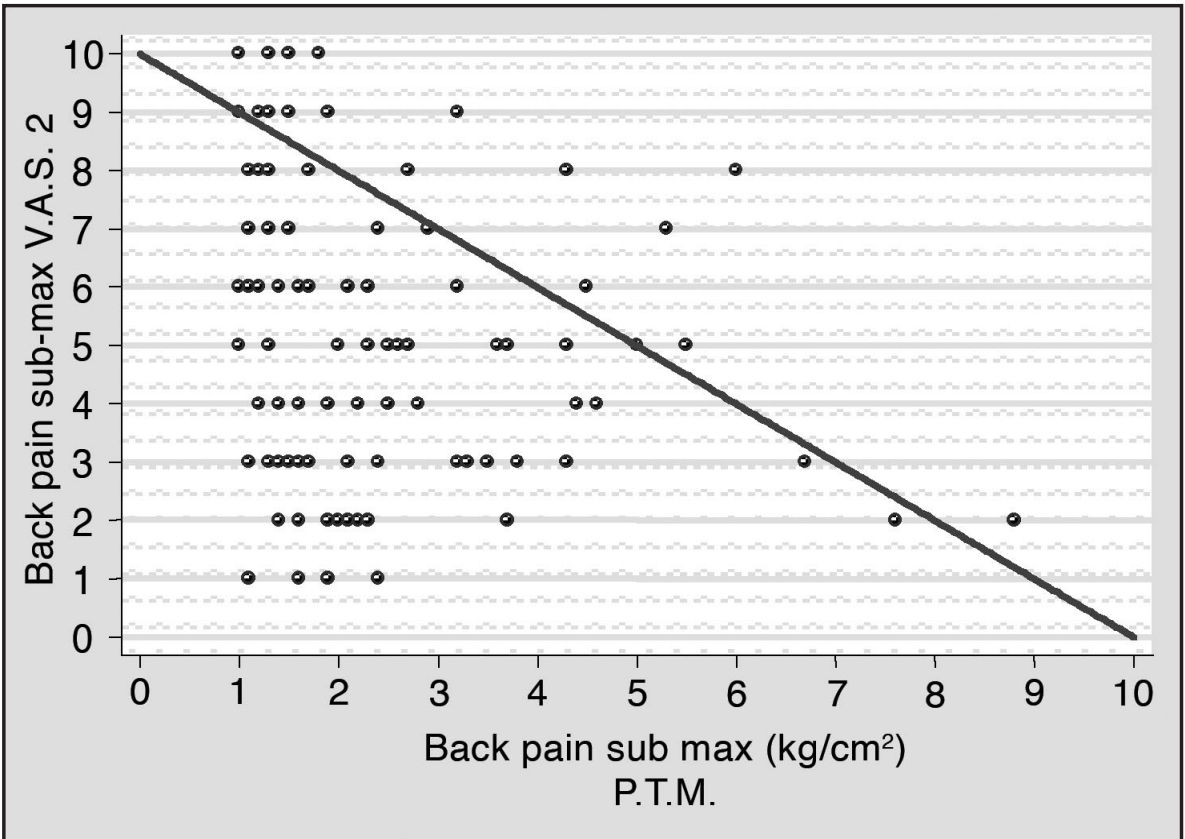

Figure 6 shows no inverse relationship exists between the sub-maximum pressure threshold readings and the V.A.S.2.

\section{REFERENCES}

Bardin LD, 2002 Physiotherapy and low back pain. Part 1: Outcomes research in the quest for evidence. South African Journal of Physiotherapy 58:3-7
Beaton DE, Bombardier C, Guillemin F 2000 Guidelines for the process of cross-cultural adaptation of self-report measures.Spine 25 ( 24):3186-3191

Bullinger M, Alonso J, Apalone G, Leplege A, Sullivan M 1998 Translating health status questionnaires and evaluating their quality: The IQoLA project approach. Journal of Clinical Epidemiology 51:913-923

Carlsson AM, 1983 Aspects of the Reliability and Validity of the Visual Analogue Scale. Pain 16: 87-101

Chang L, Toner BB, Fukudo, S 2006 Gender, Age, Society, Culture and a Patient's Perspective in the Functional Gastrointestinal Disorders.Gastroenterology 130:1435-1446

Clark P, Lavielle P, Martinez H 2003 Learning from pain scales. Patient perspective. Journal of Rheumatology 30(7) :1584-1588

Cole B, Finch E, Gouland C May N 1995 Physical Rehabilitation Outcome Measures, third edition Part 3 B Williams and Wilkens. Publishers Canadian Physiotherapy Association Canada 80-84

Ferraz MB, Quaresma MR, Aquino LR 1991Reliability of pain scales in the assessment of literate and illiterate patients with rheumatoid arthritis.Journal of Rheumatology 18 (8): 1269-127

Fischer AA 1987 Pressure algometry over normal muscles. Standard values, validity and reproducibility of pressure threshold. Pain 30: 115-126

Freeman K, Smyth C, Dallman L, Jackson B 2001 Pain measurement scales: a comparison of the visual analogue scale and faces rating scales in measuring pressure ulcer pain. Journal of Wound Ostomy Continence Nursing. 28:6 290-296

Gridley L, van den Dalder PA 2001 The percentage improvement in pain scale as a measure of physiotherapy treatment effects. Australian Journal of Physiotherapy 47: 133-138

Hansen GR, Streltzer J 2005 The Psychology of Pain.Emergency Medicine Clinics of North America 23: 339-348

Jelsma J, de Cook P, de Weerdt W 2002 The validity of the Shona version of the EQ - 5D quality of life measure. South African Journal of Physiotherapy 58(3): 8-12

Jelsma J, Chivaura V, de Weedt W, de Cook P 2000 A bridge between cultures: A report on the process of translating the EQ - 5D instrument into Shona. South African Journal of Physiotherapy 56 (4): 3-9

Jelsma J, Machiri G, Madzivire DM 1997. The use of pain measurement scales in the Zimbabwean context. Central African Journal of Medicine 43(9): 256-259 
Figure 7: Scatter plot of the sub- maximum pressure pain vs the patient perception on the V.R.S.

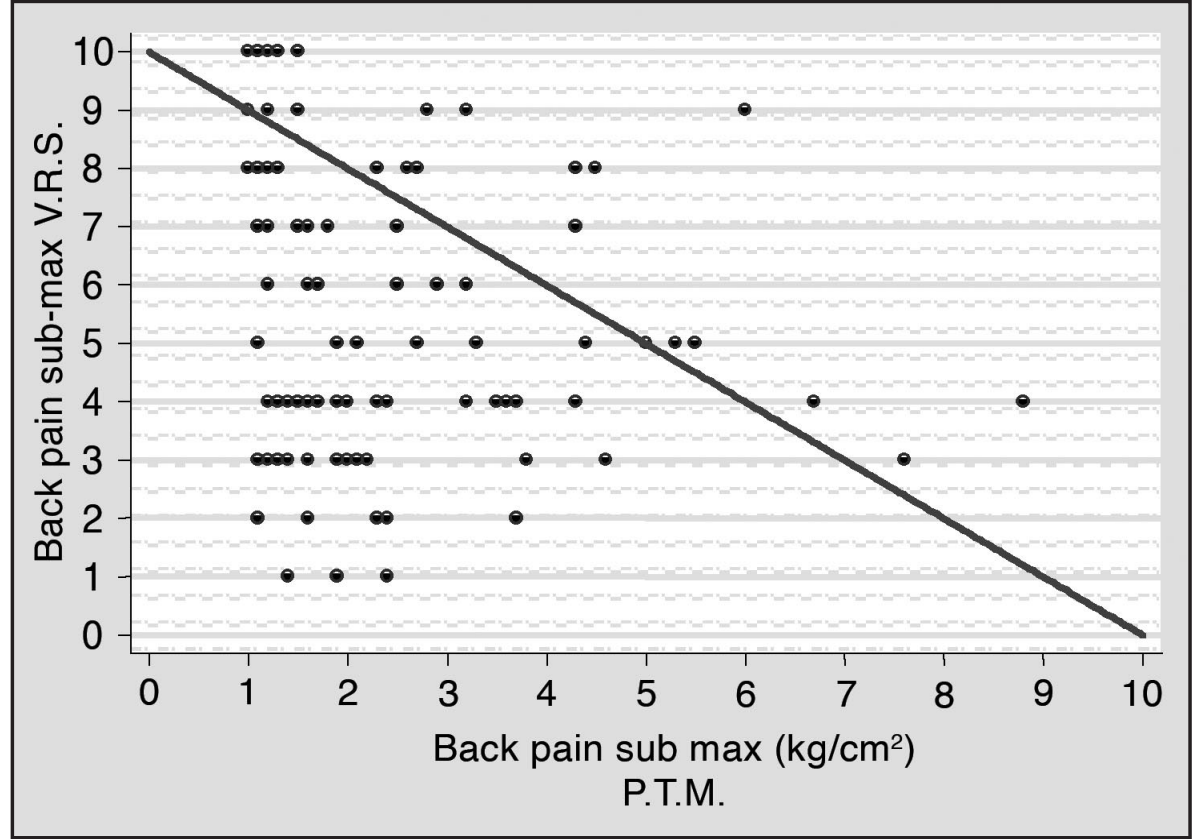

Figure 7 shows no inverse relationship exists between the sub-maximum pressure threshold readings and the V.R.S.

Figure 8: Scatter plot of the maximum pressure pain vs the patient perception on the Wong-Baker Faces pain measure.

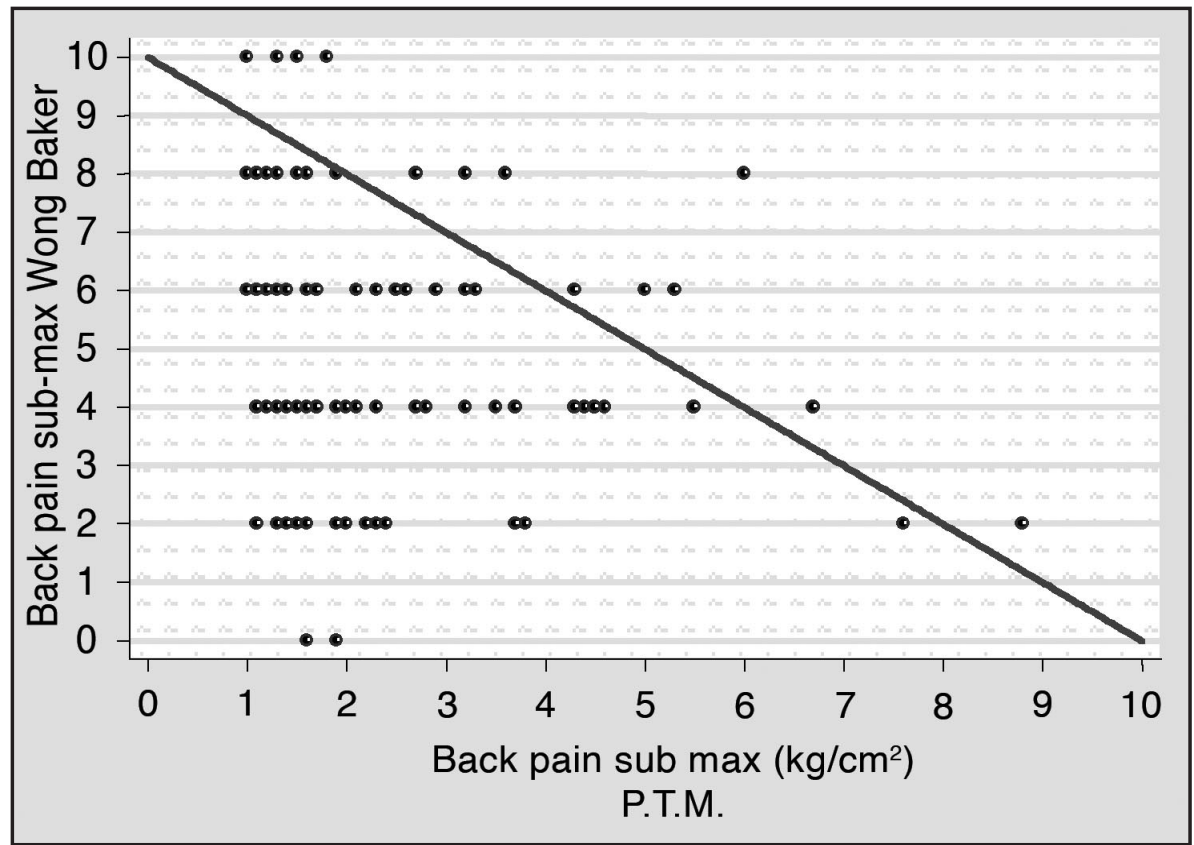

Figure 8 shows no inverse relationship exists between the sub-maximum pressure threshold readings and the Wong-Baker Faces pain measure.

Jensen MP, Turner JA, et al 1999 Comparative reliability and validity of chronic pain intensity measures. Pain 83: 157-162

Kim EJ, Buschmann MT 2006 Reliability and validity of the Faces Pain Scale with older adults.International Journal of Nursing Studies 43(4): 447-456
Kopec JA 2000 Measuring Functional Outcomes in Persons with Back Pain. Spine 25 (24): 3110-3114

Mannion AJ, Junge A, Fairbank JCT, Dvorak J, Grob D 2006.Development of a German version of the Oswestry Disability Index. Part 1: cross-cultural adaptation, Reliability and Validity. 55-65
Mersky H, Spear FG, 1964 The reliability of the pressure algometer. British Journal of Clinical Psychology 3: 130-136

Newman CJ, Lolekha R, Limkittikul Lolekha K 2005 Comparison of pain scales in Thai children. Archives of Disease in Children 90:269-270

Nuhr MJ, Crevenna R, Quittan M et al 2004 Cross-cultural adaptation of the Manniche questionnaire for German-speaking low back pain patients. Journal of Rehabilitative Medicine 36(6 ): 267-272

Ogon M, Krismer M, Sollner W 1997 Chronic low back pain measurement with visual analogue scales in different settings. Pain 71(1): 113

Olaogun M, Adedoyin RA, Anitaloba RO 2003 Reliability and concurrent validity of the Visual Analogue Scale and modified Verbal Rating Scale of pain assessment in adult patients with knee osteoarthritis in Nigeria. South African Journal of Physiotherapy 59(2): 12-15

Ostlund U, Gustavsson P, Furst CJ 2006 Translation and cultural adaptation of the piper fatigue scale for use in Sweden. European Journal of Oncology Nursing 04.034 www.sciencedirect.com

Terai T, Yukioka H, Asda A 1998 Pain evaluation in the intensive care unit: observer reported faces scale compared with selfreported visual analogue scale. Anaesthesia and Pain Medical Journal 23(2): 147-151

Teutsch C 2003 Patient- doctor communication. The Medical Clinics of North America 87: 1115-1145

Werner D, Bower B 1987 Helping Health Workers learn. Seventh edition Chapter 5: 1-18, Chapter 2: 1-18, Chapter 8: 8 Hesperian Foundation

Werner D 1988 Disabled Village Children. A guide for community health workers, rehabilitation workers and families. Second edition chapter 44:402-404, Chapter 47: 442-446, Chapter 8: 8 Hesperian Foundation

Wong D, Baker C, 1988 Comparison of assessment scales Paediatric Nursing 1:9-11

Zanoli G, Stromqvist B, Jonsson B 2001 Visual Analog Scales for Interpretation of Back and Leg Pain Intensity in Patients Operated for Degenerative Lumbar Spine Disorders 26(21): 2375-2380 